WellBeing International

WBI Studies Repository

$2-2012$

\title{
Superglue is Not Super: An Assessment of Superglue for Suturing Tag Incisions in a Cultured Marine Fish
}

\author{
Vincent Raoult \\ Macquarie University \\ Culum Brown \\ Macquarie University \\ Jane E. Williamson \\ Macquarie University
}

Follow this and additional works at: https://www.wellbeingintlstudiesrepository.org/acwp_aff

Part of the Animal Experimentation and Research Commons, Animal Studies Commons, and the Laboratory and Basic Science Research Commons

\section{Recommended Citation}

Raoult, V., Brown, C., \& Williamson, J. E. (2012). Superglue is not super: an assessment of superglue for suturing tag incisions in a cultured marine fish. Journal of the World Aquaculture Society, 43(1), 140-143.

This material is brought to you for free and open access by WellBeing International. It has been accepted for inclusion by an authorized administrator of the WBI Studies Repository. For more information, please contact wbisr-info@wellbeingintl.org.

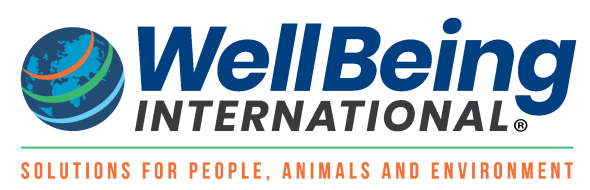




\section{Superglue is Not Super: An Assessment of Superglue for Suturing Tag Incisions in a Cultured Marine Fish}

Vincent Raoult, Culum Brown, and Jane E. Williamson

Macquarie University

Tagging is a necessary tool for many aquaculture and ecological studies, particularly in the marine environment where constant visual monitoring is extremely difficult and costly. Tagging is also widely used as a means of identifying individual fish in fisheries conservation programs. External tagging is generally thought to be the simpler form of tagging, yet the technique is plagued by many problems that include drag caused by fouling (Ross and McCormick 1981) and infection (Bergman et al. 1992). This has led researchers to use implanted tags that, in addition to containing information to identify an individual, can be used to record physiological variables such as blood temperature, heart beat rates, and movement (Cooke et al. 2004).

Since the 1980s, passive integrated transponder (PIT) tags have been increasingly used over external tags because of their ease of use and low cost (Gibbons and Andrews 2004). They are primarily used in fingerling release studies and for monitoring the movement of fish (Ombredane et al. 1998). Although it is generally agreed that PIT tags are a useful means of tracking individual fish, researchers disagree on the best method of maximizing tag retention once it has been implanted. Some advocate that traditional suturing is necessary for effective tag retention (Baras et al. 1999), while others consider it too time consuming when dealing with large numbers of fish (reviewed by Jepsen et al. 2002). From an ethical perspective, closing the wound after inserting a tag is likely to be important in terms of reducing infection. Cyanoacrylate, or superglue, has been considered as an alternative to traditional thread suturing of small wounds because of the time benefits associated with rapid application. Some aquaculturists and researchers, however, have rejected superglue as a possible suturing agent, suggesting it was too problematic to apply, not effective enough in retaining the tags and may cause inflammatory responses (Jepsen et al. 2002). However, any inflammation caused by superglue has been considered no worse than that produced by traditional suturing but has the additional benefit of reduced mortality (Skov et al. 2005).

This study used PIT tags as a part of a behavior monitoring project on a commercially cultured marine fish (Raoult et al. in press), and superglue was used as a suturing agent. The tag retention rates were compared with those of a control group and those obtained from similar published studies. The viability of cyanoacrylate as a suturing agent is discussed.

\section{Materials and Methods}

All experiments and procedures were approved by the Macquarie University animal ethics committee (Animal Research Authority 2009/008). Juvenile mulloway, Argyosomus japonicus were obtained from a commercial hatchery in Botany Bay and transported to the NSW fisheries research station at Cronulla, Sydney, Australia. They were allowed to adjust to their new surrounding for 4 weeks prior to experimentation (for more details see Raoult et al. in press). 
All fish were anesthetized by primary immersion in their holding tank using AQUI-S, a clove oil concentrate, at a concentration of $5 \mathrm{~mL} / 1000 \mathrm{~L}$. Individuals where then netted and immersed in a $100 \mathrm{~L}$ bucket of AQUI-S at a concentration of $12.5 \mathrm{~mL} / 1000 \mathrm{~L}$ until the fish lost equilibrium, which is considered the ideal state of anesthesia for surgery (Stoskopf 1993). During the procedure, fish were held upside down with a wet towel in a $v$ shaped, soft foam bed to minimize movement and reduce any potential physical damage to the individual.

One hundred and seventy-one juvenile $A$. japonicus ranging from 30 to $45 \mathrm{~cm}$ in total length and $400-800$ $\mathrm{g}$, were tagged with ID 100 Trovan PIT tags measuring $2.2 \times 11 \mathrm{~mm}$ and weighing $0.09 \mathrm{~g}(<0.001 \%$ of fish weight). These PIT tags were the smallest available at the time, and of the size often used in monitoring studies. For minimal side effects, it was agreed that tags should be under $1.75-2 \%$ of fishes' body weight (Winter 1996). Thus any adverse effects to the fish would have been more likely the result of the implantation technique than the tag itself.

Each PIT tag was injected through a sterile needle inserter posterior to the pectoral girdle in the body cavity. Wounds were immediately sealed with two to three drops of superglue to prevent bleeding and aid the healing process, then the fish were held until the superglue had started to dry ( $30 \mathrm{sec})$. After the procedure, each fish was placed in a highly aerated $100 \mathrm{~L}$ recuperation bucket and fresh seawater was gently flushed through their gills with a hose to revive it. Fish were subsequently placed in a recuperation tank with Enviro-nets where they were monitored for a period of 7 days, or until full recovery, which was defined as when the wounds had fully healed and the fish had resumed normal behavior (Alexander 1966). A control group (21 individuals) was tagged separately with identical methods, except the wound was not sealed with superglue. Several fish were sacrificed after these experiments allowing the examination of the pathological response to the tags in situ.

Table 1. Summary of study results.

\begin{tabular}{|lccc|}
\hline Treatment & Sample size & Tag retention rate (\%) & Mortality rate (\%) \\
\hline Superglued & 150 & $88 \pm 5$ & 0 \\
Control & 20 & 100 & 0 \\
\hline
\end{tabular}

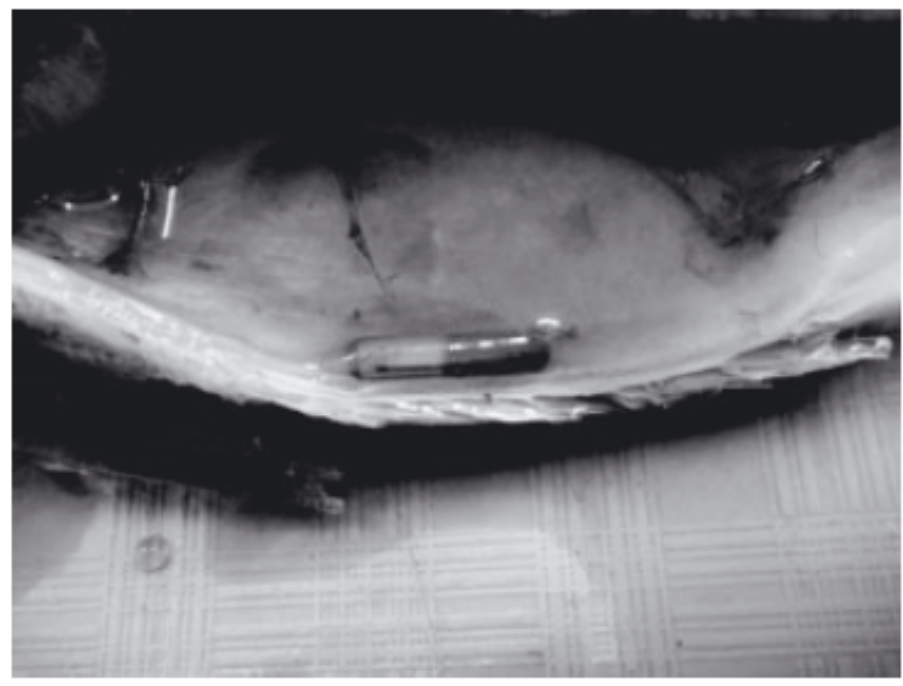

Figure 1. Post-mortem dissection of mulloway showing passive integrated transponder tag and absence of inflammation or immune responses. 


\section{Results}

No mortalities occurred as a result of PIT tag implantation over the duration of this study (over $6 \mathrm{mo}$ ). Tag retention over the study period was $88 \pm 5 \%$ for superglued individuals and all the lost tags occurred during the first week following surgery. Fish had fully healed within 4 days and accepted food the day following implantation. The control group had similar healing rates and no mortalities but significantly higher tag retention (100\%; Table 1). Examination of the tags in situ revealed that they had been completely encompassed in connective tissue and there was no sign of inflammation or a broader immune response (Fig. 1).

\section{Discussion}

Only $12 \%$ of 150 implanted tags were lost when applying superglue to the pit tag insertion wound. In comparison, none of the controls (21 fish), where no superglue was applied, lost their tags. The results suggest that $A$. japonicus was resilient to PIT tag implantation and that no suturing agents are necessary when inserting small tags into large fish. None of the tags failed and lost tags were later recovered from the bottom of the holding tank. Lower tag retention rates than the control group may have been caused by the superglue interfering with normal healing processes that allowed for additional time for tag rejection.

The tag rejection rates obtained in this study using superglue as a suturing agent were similar to those using traditional suturing (Baras et al. 1999; 0-10\%), although mortality rates in this study were lower. In some studies, the syringe was not preferred to implant tags because of high mortality rates (up to 50\%) and it was considered unnecessary to suture the resulting incision because of its small size of less than 4 mm (Baras et al. 1999; Jepsen et al. 2002; Acolas et al. 2007). Other studies that insert small non-PIT implants through incisions under $1 \mathrm{~cm}$ in length also abstain from suturing the incision (Shelton and Mims 2003).

In this study, substantial hemorrhaging was observed following implantation in the brief time before the cyanoacrylate was applied. Once the superglue was applied the hemorrhaging stopped immediately. In the control groups, application of pressure over the wound for a brief time also prevented further hemorrhaging. Thus, if large numbers of fish are to be tagged and there is no time to treat the wound by the application of pressure, then superglue may be beneficial in terms of preventing blood loss. Superglue had the advantage of speed over suturing, and the hemorrhaging was stopped much faster than it would have been had thread been used. From an animal welfare perspective, thread suturing could cause the fish additional distress because of the duration and nature of the procedure, thus superglue is superior in this regard. Moreover, the adhesive was unaffected by water and separated from the fish within a week, requiring no intervention. This was a problem for traditional suturing, which often results in suture material being retained permanently (Jepsen et al. 2002). The healing rate of less than 7 days was faster than other species that had undergone similar surgical procedures (Nemetz and Macmillan 1988). Finally, the tag was found to be completely encased in connective tissue and there were no signs of immune responses (Fig. 1) which confirms Nemetz and Macmillan's (1988) conclusions that cyanoacrylate does not produce significant inflammatory responses.

The size of the required incision appears to be a crucial factor in determining the effectiveness of superglue as a suturing agent. Baras et al. (1999), for example, found suturing was necessary in small tilapia (2-14 g) on 2-4 mm incisions due to protrusion of viscera. In these cases, perhaps a single suture could be applied to close the wound and superglue could then be added to seal it. Although the effectiveness of cyanoacrylate adhesive on larger incisions remains to be documented, it is likely to be more effective than leaving the incision without any treatment. Thus, for incisions under $2 \mathrm{~mm}$ in mediumsized fish, the authors suggest that no suturing be performed unless excessive blood loss or infection is a 
concern. If rapid suturing is necessary to prevent blood loss then superglue may be a superior alternative to traditional suturing in aquaculture and fisheries management, along with conservation studies, but has little discernible effect on tag retention.

\section{Acknowledgments}

Thanks to the Fisheries Division, Department of Industry and Investment, NSW Cronulla research facility for providing the necessary facilities for the experiments, without which none of this project would have been possible. Thanks to Dave Barker for his help in numerous aspects of the project as well as providing basic care for the animals. C. B. was supported by an ARC Australian Research Fellowship.

\section{Literature Cited}

Acolas, M. L., J. M. Roussel, J. M. Lebel, and J. L. Bagliniere. 2007. Laboratory experiment on survival, growth and tag retention following PIT injection into the body cavity of juvenile brown trout (Salmo trutta). Fisheries Research 86:280-284.

Alexander, R. M. 1966. Physical aspects of swim bladder function. Biology Reviews 41:141-176.

Baras, E., L. Westerloppe, C. Melard, J.-C. Philippart, and V. Benech. 1999. Evaluation of implantation procedures for PIT-tagging juvenile Nile tilapia. North American Journal of Aquaculture 61:246251.

Bergman, P. K., F. Haw, H. L. Blankenship, and R. M. Buckley. 1992. Perspectives on design, use, and misuse of fish tags. Fisheries 17:20-25.

Cooke, S. J., S. G. Hinch, M. Wikelski, R. D. Andrews, L. J. Kuchel, T. G. Wolcott, and P. J. Butler. 2004. Biotelemetry: a mechanistic approach to ecology. Trends Ecology and Evolution 19:334-343.

Gibbons, J. W. and K. M. Andrews. 2004. PIT tagging: simple technology at its best. BioScience 54:447454.

Jepsen N., A. Koed, E. B. Thorstad, and E. Baras. 2002. Surgical implantation of telemetry transmitters in fish: how much have we learned? Hydrobiologia 483: 239-248.

Nemetz, T. G. and J. R. Macmillan. 1988. Wound healing of incisions closed with cyanoacrylate adhesive. Transactions of the American Fisheries Society 117:190-195.

Ombredane, D., J. L. Bagliniere, and F. Marchand. 1998. The effects of passive integrated transponder tags on survival and growth of juvenile brown trout (Salmo trutta L.) and their use for studying movement in a small river. Hydrobiologia 371-372:99-106.

Raoult, V., C. Brown, A. Zuberi, and J. E. Williamson. Blood cortisol concentrations predict boldness in juvenile mulloway (Argyosomus japonicus). Journal of Ethology. In press.

Ross, M. J. and J. H. McCormick. 1981. Effects of external radio transmitters on fish. Progressive Fish Culturist 43:67-72.

Shelton, W. L. and S. D. Mims. 2003. Fabrication of silastic implants for in vivo steroid delivery in fish. North American Journal of Aquaculture 65:158-161.

Skov, C., J. Brodersen, C. Bronmark, L.-A. Hansson, P. Hertonsson, and P. A. Nilsson. 2005. Evaluation of PIT-tagging in cyprinids. Journal of Fish Biology 67:1195-1201.

Stoskopf, M. 1993. Aneasthesia. Pages 161-167 in L. Brown, editor. Aquaculture for veterinarians. Pergamon Press, Oxford.

Winter, J. D. 1996. Advances in underwater biotelemetry. Pages 555-590 in B. R. Murphy and D. W. Willis, editors. Fisheries techniques, 2nd edition. American Fisheries Society, Bethesda, Maryland. 